\title{
Numerical and Field Investigations on Rockburst Risk Adjacent to Irregular Coal Pillars and Fault
}

\author{
Zhi-long He $\mathbb{D}^{1},{ }^{1}$ Cai-ping Lu $\mathbb{D}^{1},{ }^{1}$ Xiu-feng Zhang, ${ }^{2}$ Chao Wang, ${ }^{2}$ Bao-qi Wang, ${ }^{3}$ \\ and Tao Zhou ${ }^{3}$ \\ ${ }^{1}$ School of Mining Engineering, Key Laboratory of Deep Coal Resource Mining (Ministry of Education), \\ China University of Mining and Technology, Xuzhou, Jiangsu 221116, China \\ ${ }^{2}$ Centre of Rockburst Prevention Research, Yankuang Group Co., Ltd., Jining 250000, Shandong, China \\ ${ }^{3}$ Zhaolou Coal Mine, Yankuang Group Co., Ltd., Heze 274000, Shandong, China \\ Correspondence should be addressed to Cai-ping Lu; cplucumt@126.com
}

Received 15 May 2020; Revised 23 November 2020; Accepted 24 December 2020; Published 4 February 2021

Academic Editor: Hongwei Yang

Copyright (c) 2021 Zhi-long He et al. This is an open access article distributed under the Creative Commons Attribution License, which permits unrestricted use, distribution, and reproduction in any medium, provided the original work is properly cited.

Irregular coal pillars are often reserved in the upper coal seam in multiseam mining due to the limitation of geological conditions and mining methods. Diffused and transmitted stress in the pillars will form the stress concentrated areas in the lower coal seam and will increase the risk of rockburst. Based on the upper irregular pillars and fault encountered in the 7301 working face of the Zhaolou coal mine, this paper studies the evolution of stress and energy when the working face passed through the area affected by pillars. The adopted methods include numerical simulations and field monitoring. The change in stress concentration factor and stress gradient because of the mining activities in lower coal seam was analyzed by numerical simulation, indicating that the stress gradient reaches a peak when the working face is closed to the area under the edge and junction of pillars, which has the high risk of inducing rockburst. The sources' location, variation rule of microseismic (MS) total energy and events, frequency spectrum distributions, and source parameters are discussed, respectively, based on the field monitoring data. The main conclusions were obtained as follows: (1) The total energy and event counts reach the peak when working face is close to the area under the edge and the junction of pillars. (2) The dominant frequency transfers from high frequency to low frequency, the stress drop reaches the peak value, the energy index decreases sharply, and the cumulative apparent volume increases sharply, which all are obvious precursory characteristics before rockburst.

\section{Introduction}

Most coal exists in the state of multiple coal seams. With the increase of the mining intensity, an increasing number of underground coal mines have begun to exploit coal seams with close distance to each other [1-5]. Due to the limitation of the geological conditions and the layout of the mining area, pillars are often left in the upper coal. The coal pillar is affected by the overburden of the goaf, which produces the stress concentration and transfers it downward, causing the stress redistribution of the lower coal seam [6-8]. When the lower layer coal mining enters area affected by pillars, the abutment pressure and the additional stress transferred by pillars are superposed, which greatly increases the risk of rockburst.

Problems of residual pillars in multiseam mining have been studied by many researchers, and the subject has been well discussed in the literature. Regarding the strength characteristics of pillars, Wattimena et al. [9] utilized logistic regression to calculate the probability that a particular pillar of a given geometry (width-to-height ratio) and a known stress condition (strength-to-stress ratio) will be stable. Khanal et al. [10] investigated the effects that seam separation distances, mining offset, panel layout, and panel orientation each have on surface subsidence and chain pillar stress magnitude taking numerical simulation. Mohan et al. [11] showed the results of numerical modelling of failed and stable cases of pillars from Indian coal 
mines using FLAC3D in the strain-softening mode. Kaiser et al. [12] explored the limitations and potential opportunities in pillar design and considered pillar designs based on current empirical rules may be inadvertently conservative. Alber et al. [13] discussed the failure behavior of pillar using the theory of fracture mechanics. Esterhuizen et al. [14] proposed a method of estimating the pillar strength and selecting a safety factor for design based on observations of stable and failed pillars, supplemented by numerical models. These researches lay a foundation for further understanding the strength characteristics of pillars.

With respect to the stress redistribution under coal pillar, Suchowerska et al. [15] attempted to identify the variables that affect stress redistribution in the strata under the supercritical longwall panels in the way of Wilson's equations in conjunction with finite element modelling. Yan et al. [16] calculated the depth of the strata affected by the concentrated stress imparted by established gob coal pillars and the effective range of energy density concentration. Liu et al. [17] analyzed the diffusion angle of the pillar floor by using UDEC and proposed the optimization suggestions for roadway layout. Zhu et al. [18] carried on FLAC3D numerical simulation of vertical stress field and deformation field under different coal pillar width in order to investigate the protected layer pressure relief effect under the influence of different width of coal pillar. Yang et al. [19] calculated the stress of strata under pillars with linear load by the calculation method for uniform load. Yu et al. [20] evaluated the performance of coal pillars under weak roof based on stress and deformation field monitoring.

The studies mentioned above make a great contribution to stress redistribution under coal pillar. But these studies mainly focus on the stress distributions under a single regular coal pillar. When there are irregular and multiple residual pillars, the stress distribution will become more complex due to stress superposition of adjacent pillars. At the same time, most of the above researches are based on the simplified theoretical model and numerical simulation, which may be not applicable to irregular pillars due to the lack of the support of field monitoring data. Microseism, a technology by receiving the elastic wave in the process of fracture and deformation of coal and rock, has a wide range of monitor in space and time and has wide application in rockburst prediction. By comprehensive analysis of the received waveform and a series of source parameters [21-25], the location, time, energy, and even the failure form of rock mass of the microseism can be obtained, thus profoundly revealing the whole process of the rockburst from its initiation to outbreak. The purpose of this paper is to discuss the influence of the residual pillars and fault on the mining of the lower coal seam. Therefore, through numerical simulation and field monitoring, we explore the stress redistribution of the pillars and the lower working face, as well as the characteristics of MS source location, energy, and frequency variation. The conclusions of this research can provide references for the safe mining of working face under the similar geological conditions.

\section{Field Conditions}

As shown in Figure 1, the average buried depth of 7301 working face in the Zhaolou coal mine is approximately $1000 \mathrm{~m}$, where the fully mechanized top-coal caving mining technique is adopted. The mining width of the working face is $230 \mathrm{~m}$, and the lengths of the headentry and tailentry are 1691 and $1664 \mathrm{~m}$, respectively. The \#3 coal seam with relatively simple structure is mainly mined, the thickness is $6.8-9.0 \mathrm{~m}$ with the average of $7.8 \mathrm{~m}$, and the dip angle is $1-13^{\circ}$ with the average of $3.5^{\circ}$. The immediate roof is composed of sandstone and mudstone with $2.93 \mathrm{~m}$ in thickness, the main roof consists of $9.61 \mathrm{~m}$-thick fine sandstones, and the immediate floor is composed of tone and mudstone with $10.85 \mathrm{~m}$-thick mudstone. The headentry is adjacent to the FZ14 thrust reverse fault with $50-70 \mathrm{~m}$ throw in the northern direction; meanwhile, the \#3 mining area adjoining to the 7301 working face has been mined out. The irregular coal pillars are expected to lead to complex stress distributions in 7301 working face.

From Figure 1, it appears that irregular pillars are close to headentry, the minimum horizontal distance between them is only $60 \mathrm{~m}$, and the vertical distance is $50-70 \mathrm{~m}$. As a result, the vertical stress will increase in the headentry side of the working face due to the imposed extravertical load by pillars. At the same time, the tectonic stress near the FZ14 fault will also affect the working face. The rockburst may be induced by the superposition of the abutment pressure, additional stress transmitted by pillars, and tectonic stress near the fault with the advance of the working face.

\section{Numerical Simulation}

3.1. Modelling. As it is difficult to monitor the stress variation in the field in real time, numerical simulation is a proper method at the current stage to study stress characteristics at different mining stages. Based on the actual geological conditions of the Zhaolou coal mine, a simplified numerical model is established in FLAC3D software as shown in Figure 2. The length, width, and height of the model are $2000 \mathrm{~m}, 1000 \mathrm{~m}$, and $260 \mathrm{~m}$, respectively. The model includes a total of 1.06 million elements. The bottom boundary of the model is fixed in the vertical direction, and the four boundaries are fixed in the horizontal direction; the top is free. The buried depth of the bottom of the model is $1000 \mathrm{~m}$, and the gravity gradient is $0.025 \mathrm{MPa} / \mathrm{m}$; the vertical $z$-axis $\sigma_{z}$ of $-20.5 \mathrm{MPa}$ is loaded on the top boundary. The lateral pressure coefficient is set to 1.5; therefore, the horizontal $x$-axis $\sigma_{x}$ of $-27.75 \mathrm{MPa}$ and the horizontal $y$-axis $\sigma_{y}$ of $-27.75 \mathrm{MPa}$ are loaded on the four sides of the boundary. The Mohr-Coulomb model is chosen to determine elements' strength failure. The mechanical parameters are determined according to the geological surveys and the rock tests conducted in the laboratory. The uniaxial compressive strength (UCS), elastic modulus, and Poisson's ratio are obtained based on uniaxial compression test, the tensile strength is obtained from Brazilian splitting test, and the cohesion and internal frictional angles are obtained from the shear test. Figure 3 shows the photos before and after the test, and the obtained mechanical parameters are shown in Table 1. 


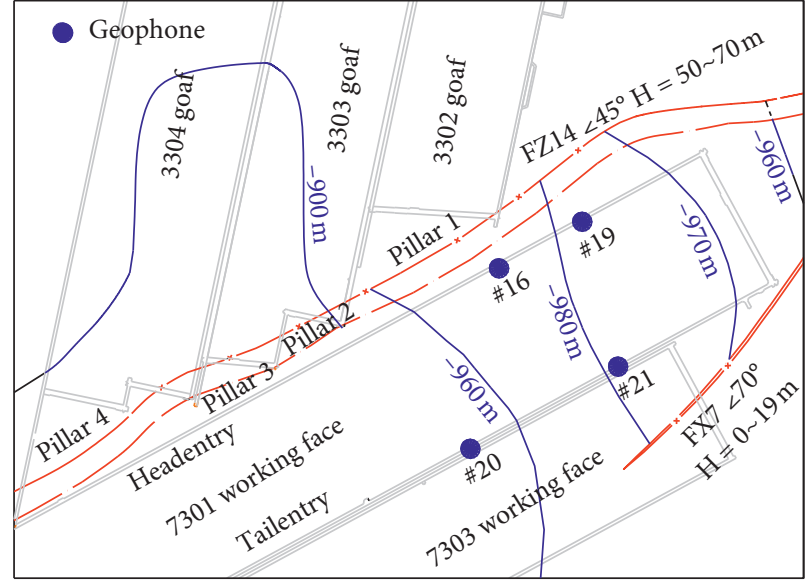

(a)

\begin{tabular}{|c|c|c|}
\hline Lithology & Bore illustration & $\begin{array}{c}\text { Thickness } \\
\text { (m) }\end{array}$ \\
\hline Mudstone & & 4.80 \\
\hline $\begin{array}{c}\text { Fine } \\
\text { sandstone }\end{array}$ & - & 5.4 \\
\hline Mudstone & & 4.5 \\
\hline $\begin{array}{c}\text { Fine } \\
\text { sandstone }\end{array}$ & & 9.61 \\
\hline $\begin{array}{c}\text { Medium } \\
\text { sandstone }\end{array}$ & I & 2.93 \\
\hline $\begin{array}{c}\text { Fine } \\
\text { sandstone }\end{array}$ & & 2.93 \\
\hline 3 \# coal & & 7.8 \\
\hline Siltstone & & 9.61 \\
\hline $\begin{array}{c}\text { Fine } \\
\text { sandstone }\end{array}$ & & 3.7 \\
\hline
\end{tabular}

(b)

Figure 1: The plane layout of the 7301 working face and lithology of coal and rock strata. (a) The plane layout of the 7301 working face. (b) Lithology of coal and rock strata.

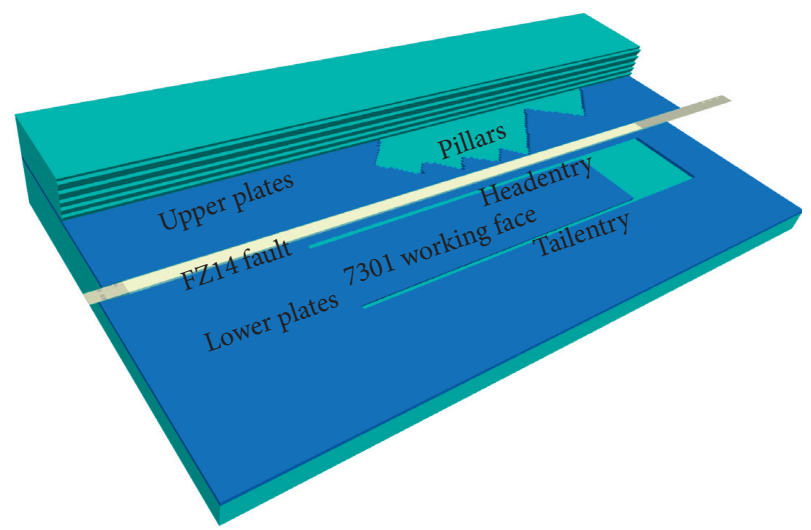

FIgURE 2: 3D numerical model.

3.2. Fault Setting. Generally speaking, in FLAC3D, mechanical properties of faults can be represented in two different ways: the interface element without thickness and the solid element with different mechanical properties. Compared with the real geological conditions, if the size of the fault in the numerical model can be ignored, then interface representation is probably more appropriate [26].

Different constitutive models are assigned in solid elements with specific thickness to reflect the characteristics of faults. The ubiquitous-joints model is found to be a representative choice. This model accounts for the presence of an orientation of weakness (weak plane) in a FLAC3D Mohr-Coulomb model. The criterion for failure on the plane, whose orientation is given, consists of a composite Mohr-Coulomb envelope with tension cutoff. The strongly anisotropic mechanical behavior can be reflected due to the existence of weak plane. The advantage of using the ubiquitous-joints model is able to account for the heterogeneity of faults and the mechanical interaction between the weak plane and the intermediate matrix. At the same time, Frederic Cappa [26] pointed out the same results can be obtained when the fault is simulated by the ubiquitous-joints model as by the interface, and the premise is the same Coulomb strength parameters are used. The FZ14 fault shown in Figure 1 is distributed almost along the whole strike, and its average thickness is about $40 \mathrm{~m}$. The thickness of the fault will affect the relative position of the pillars and the working face in the horizontal direction, and then affect the stress distribution of the lower coal seam. Therefore, the size of fault cannot be ignored for the key problems studied. It is a more suitable choice to use the solid elements with the ubiquitous-joint model.

The mechanical parameters used to simulate faults are presented in Table 1. Considering that the existence of weak matrix and weak planes in the fault will reduce its elastic modulus, the elastic modulus is set to a lower value (one tenth of siltstone) [27]. Relatively lower values of tensile strength and cohesion are used to represent the features of low fault strength. The direction of weak planes is parallel to dip of fault.

The plan of excavation simulation is as follows: (1) when numerical model reaches equilibrium, the \#3 mining area is excavated to form irregular pillars. The stress distribution of each pillar and lower coal seam were observed. (2) During mining of the 7301 working face, the evolution of vertical stress of the area under the pillars is investigated. 


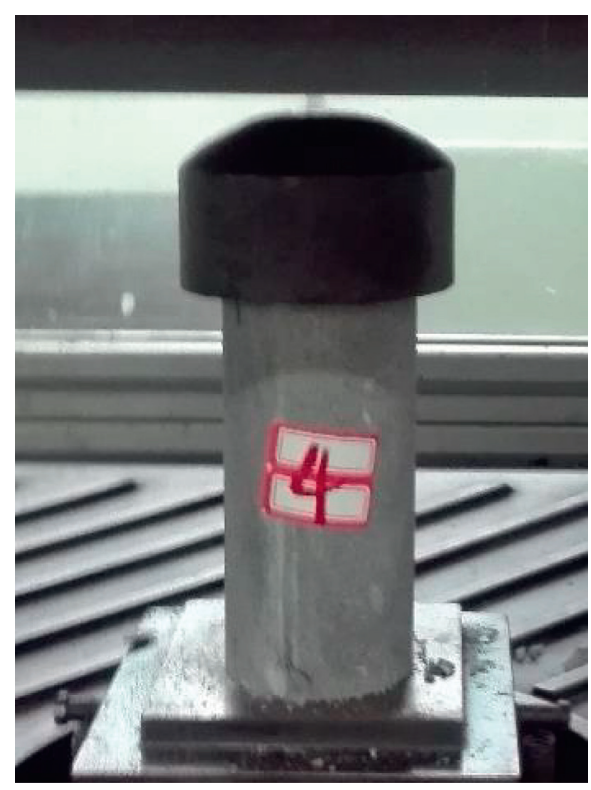

(a)

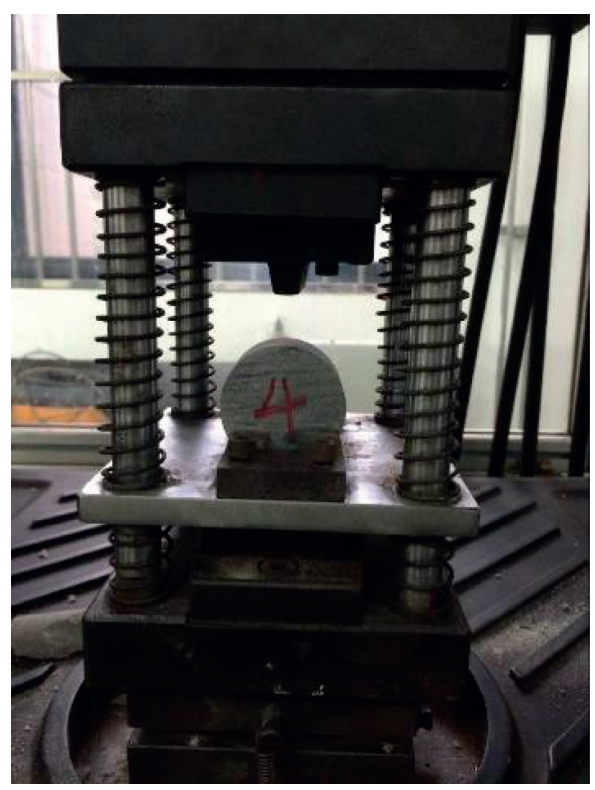

(c)

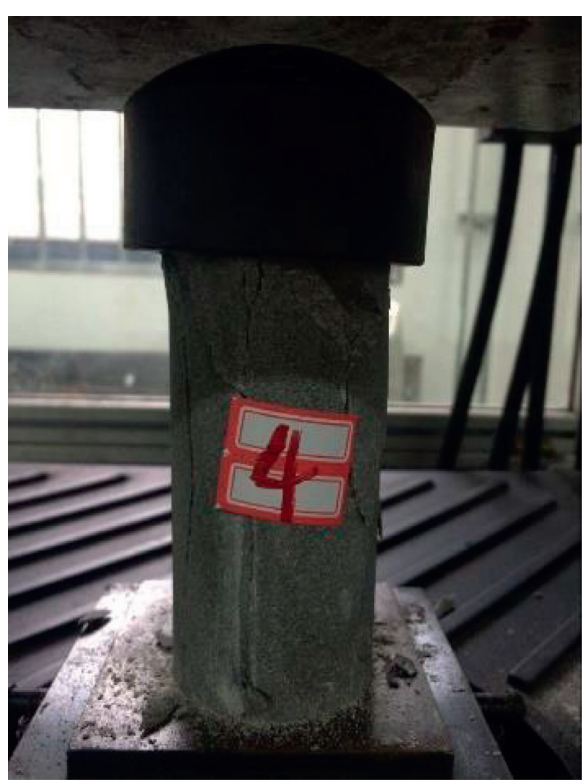

(b)

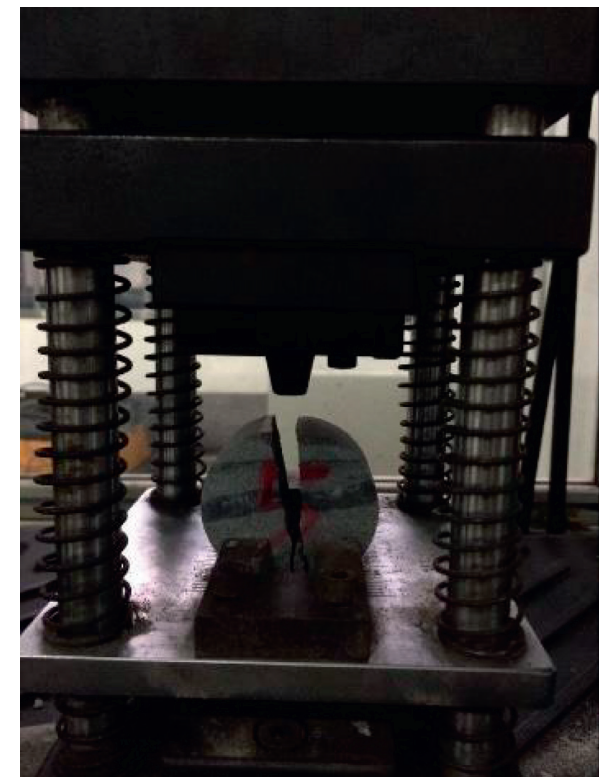

(d)

Figure 3: Continued. 


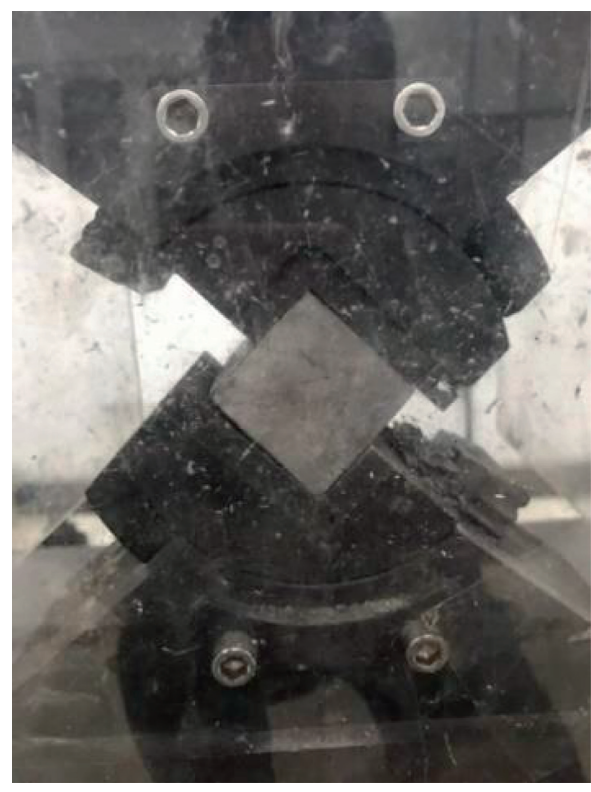

(e)

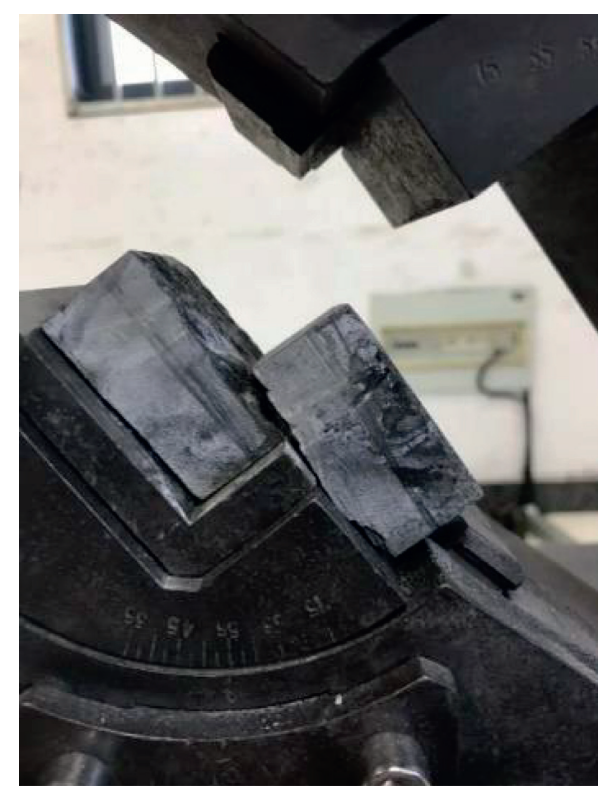

(f)

Figure 3: Experimental photos in the laboratory. (a) Before uniaxial compression test. (b) After uniaxial compression test. (c) Before Brazilian splitting test. (d) After Brazilian splitting test. (e) Before shear test. (f) After shear test.

TABLE 1: Mechanical parameters of the model.

\begin{tabular}{|c|c|c|c|c|c|c|c|}
\hline Mineral & $\begin{array}{l}\text { UCS } \\
(\mathrm{MPa}) \\
\end{array}$ & $\begin{array}{c}\text { Elastic modulus } \\
(\mathrm{GPa})\end{array}$ & $\begin{array}{l}\text { Poisson's } \\
\text { ratio }\end{array}$ & $\begin{array}{c}\text { Cohesion } \\
(\mathrm{MPa})\end{array}$ & $\begin{array}{c}\text { Internal frictional } \\
\text { angle }\left({ }^{\circ}\right)\end{array}$ & $\begin{array}{c}\text { Tensile strength } \\
(\mathrm{MPa})\end{array}$ & Density $\left(\mathrm{kg} / \mathrm{m}^{3}\right)$ \\
\hline Mudstone & 32 & 17.7 & 0.26 & 1.2 & 32 & 0.58 & 2500 \\
\hline Fine sandstone & 45 & 25 & 0.2 & 2.75 & 38 & 1.84 & 2700 \\
\hline$\# 3$ coal & 18 & 5.3 & 0.32 & 1.25 & 28 & 0.15 & 1350 \\
\hline Siltstone & 68 & 33.4 & 0.23 & 3.2 & 42 & 1.29 & 2500 \\
\hline $\begin{array}{l}\text { Medium } \\
\text { sandstone }\end{array}$ & 30 & 10.85 & 0.18 & 2.45 & 38 & 2.01 & 2600 \\
\hline Fault & - & 3.3 & 0.25 & 0.32 & 25 & 0.12 & 2200 \\
\hline
\end{tabular}

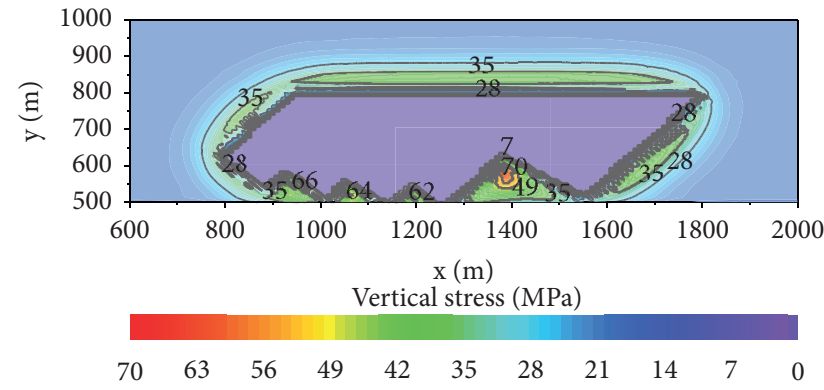

FIgURE 4: The vertical stress distribution of pillars.

3.3. Vertical Stress Distribution of the Pillars and Working Face. The vertical stress distribution in pillars is shown as Figure 4. After the coal is extracted, the abutment pressure will form on one side of the pillar, and then the abutment pressure on both sides will superpose, which causes a high stress concentration area to form in the center of each pillar. Besides, it can be clearly seen in Figure 4 that the maximum value of the stress of the pillars is closely related to its size.
The maximum vertical stress of pillar 1 reaches $70 \mathrm{MPa}$; however, that of coal pillars 2, 3, and 4 are only about 62, 64, and $66 \mathrm{MPa}$, respectively. Compared to other three pillars, the width of goafs on both sides of pillar 1 is wider, the caving height of overlying strata is higher after mined, and the hanging area of broken strata is larger, which causes higher concentrated stress to form in pillar 1. In general, the whole area of irregular pillars presents stress concentration in various degrees and redistribution of the lower coal seam stress.

Figure 5 shows the vertical stress distribution in 7301 working face. It is clearly shown that the vertical stress in the headentry side rises sharply, indicating that the stress transfer from pillars is obvious. The vertical stress in area under pillar 1 is the maximum, i.e., the peak value located at the headentry side reaches $36 \mathrm{MPa}$, and the peak vertical stress in area under coal pillars 2,3 , and 4 is $31-32 \mathrm{MPa}$, which is located at the middle of the working face. The width and stress concentration of the pillars is responsible for these differences. The concentrated stress in pillar 1 is the highest, 

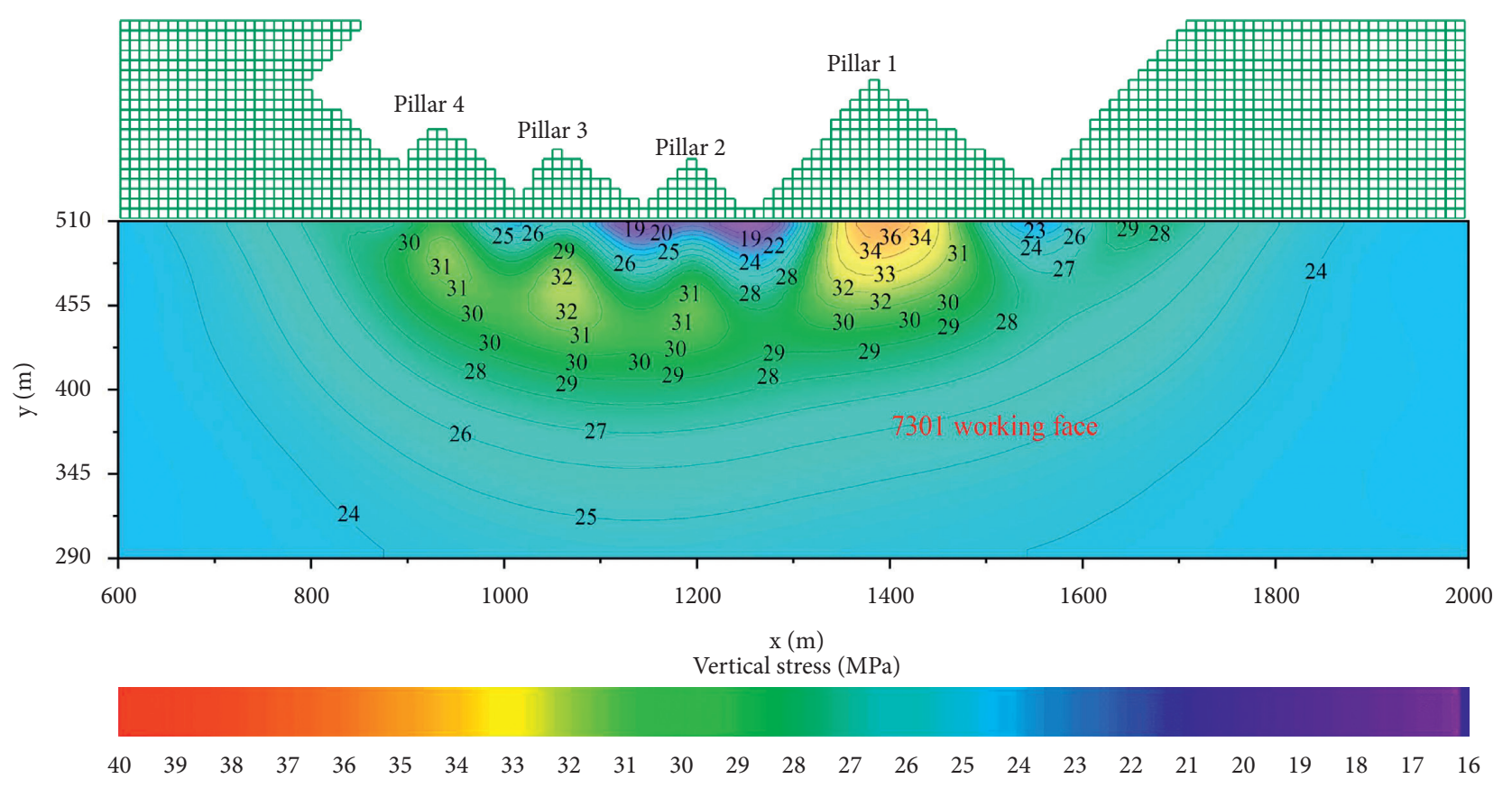

Figure 5: The vertical stress distribution of working face with influence of pillars.

as the transferred additional stress in working face is larger accordingly.

The formation of goafs on both sides will lead to the formation of stress concentration area near the sharp corner in the triangular coal pillar due to the superposition of abutment pressure on each side. The distance from the peak of abutment pressure to the coal wall is generally $5-30 \mathrm{~m}$. Therefore, if the width of the pillar is smaller, the distance between the stress concentration area of pillar and the working face is smaller in the horizontal direction, but the corresponding influence on the working face is greater. In order to study the relationship between the width of pillars and the additional stress transferred to the lower coal seam, the profile of the model is made along the middle of each pillar, as shown in Figure 6. The additional stress is equal to the difference between the vertical stress of the lower coal seam after the pillar is formed and in situ stress $(23 \mathrm{MPa})$.

In Figure 6, the lower additional stress (less than $5 \mathrm{MPa}$ ) is plotted in red to clearly observe the range of additional stress growth in lower coal seam caused by pillars. Among the pillars, the vertical stress in pillar 1 is the largest, but the width of pillar 1 in the profile is also the largest $(182 \mathrm{~m})$, thus the area with the peak stress is further away from the lower coal seam, and the corresponding range of additional stress is the smallest, only $57 \mathrm{~m}$. For coal pillar 2, although the width is the minimum only $50 \mathrm{~m}$, the area with the peak stress is the closest to the lower coal seam. However, the peak stress is the lowest, and the range of the larger additional stress in lower coal seam is smaller compared with that in pillars 3 and 4, but larger than that of pillar 1. To sum up, it can be seen that the peak stress in pillars and the horizontal distance between the pillars and the lower coal seam are the main factors affecting the stress distribution in the working face. When the peak stress in pillars is low or far from the working face, the affected area of working face is relatively small.

3.4. Stress Variation with Advancing of the Working Face. The high stress concentration area formed in the center of every pillar contributes to the appearance of multiple stress peaks at the working face along the strike. With the gradually advancing to underneath pillars, the abutment pressure will overlap with the additional stress, which causes the vertical stress in working face to rise sharply, and the increasing risk of rockburst. The stress evolution described above is shown as Figure 7.

Figure 8 shows the evolution of vertical stress in the lower coal seam before and after passing through the affected area. It can be seen from Figure 8 that the location and distribution of the peak vertical stress change obviously. When mining area is not affected by pillars (Figures 8(a) and 8(f)), the additional stress in the front of the working face is small, and the peak value of the vertical stress is mainly the abutment pressure, about 50.98-52.69 MPa. When mining in the pillars affecting area, due to the superposition of additional stress and abutment pressure, the maximum vertical stress value reaches $73.17 \mathrm{MPa}$ (Figure $8(\mathrm{~d})$ ).

Figure 9 shows the variation of vertical stress concentration factor and stress gradient (with interval of $20 \mathrm{~m}$ ) in different mining stages when mining under the pillars. It can be seen that the stress concentration factor increases obviously with the face advancing to area under pillars. Among pillars, the stress concentration factor achieves the maximum when working face is under pillar 3 , the second is under pillar 2 and coal pillar 4, and the minimum is under pillar 1. The stress gradient varying curve shows that the 
Additional stress (Szz)

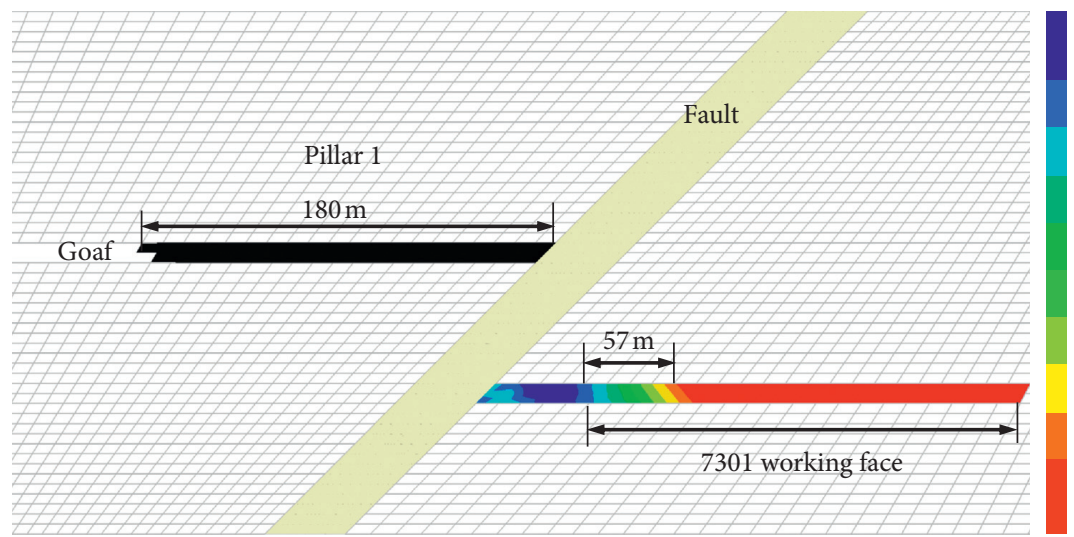

$1.0000 E+01$

$9.5000 E+00$

$9.0000 E+00$

$8.5000 E+00$

$8.0000 E+00$

$7.5000 E+00$

$7.0000 E+00$

$6.5000 E+00$

$6.0000 E+00$

$5.5000 E+00$

$5.0000 E+00$

(a)

Additional stress (Szz)

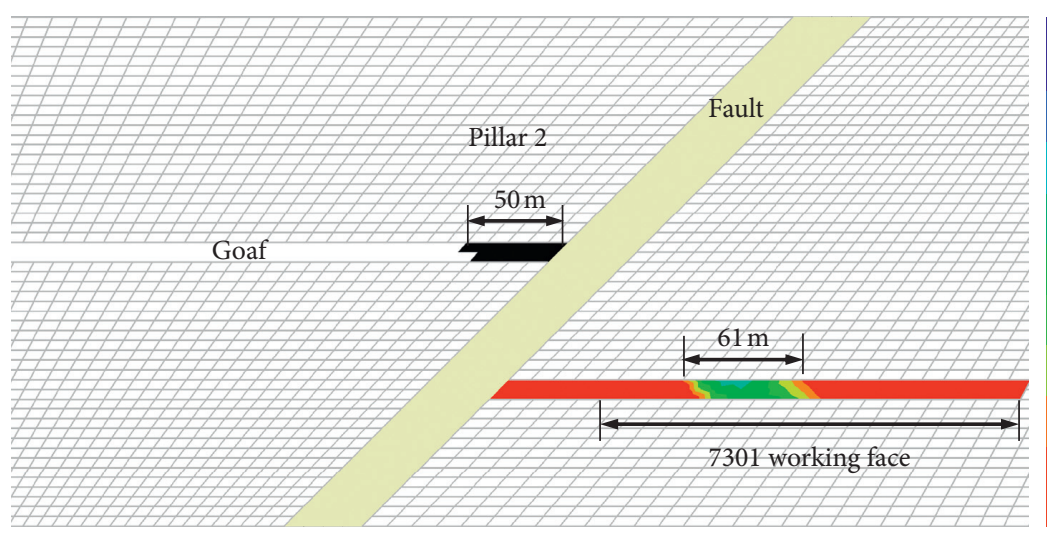

$6.6000 E+00$

$6.4000 E+00$

$6.2000 E+00$

$6.0000 E+00$

$5.8000 E+00$

$5.6000 E+00$

$5.4000 E+00$

$5.2000 E+00$

$5.0000 E+00$

(b)

Additional stress (Szz)

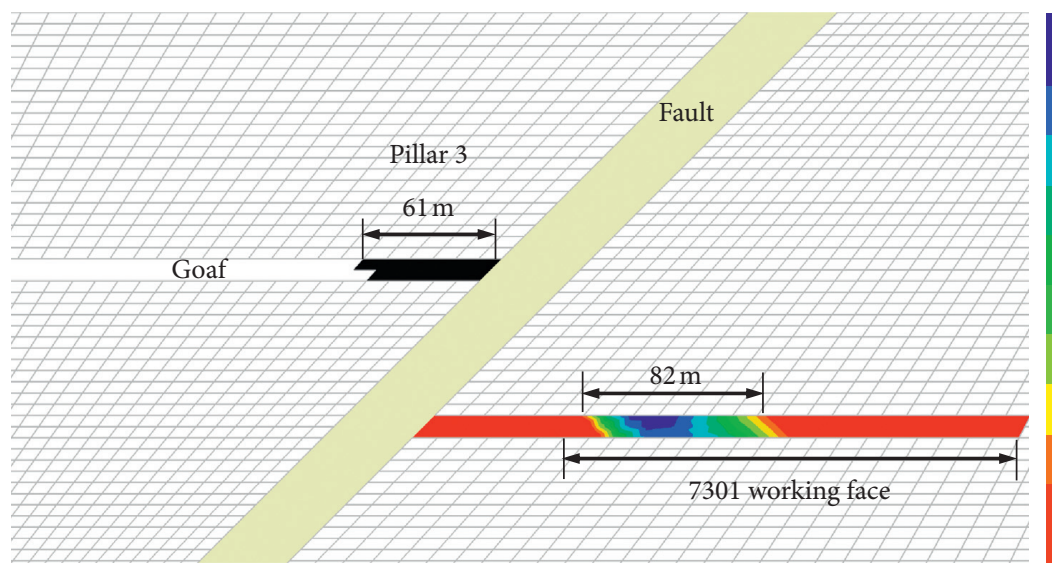

$7.0000 E+00$

$6.8000 E+00$

$6.6000 E+00$

$6.4000 E+00$

$6.2000 E+00$

$6.0000 E+00$

$5.8000 E+00$

$5.6000 E+00$

$5.4000 E+00$

$5.2000 E+00$

$5.0000 E+00$

(c)

Figure 6: Continued. 


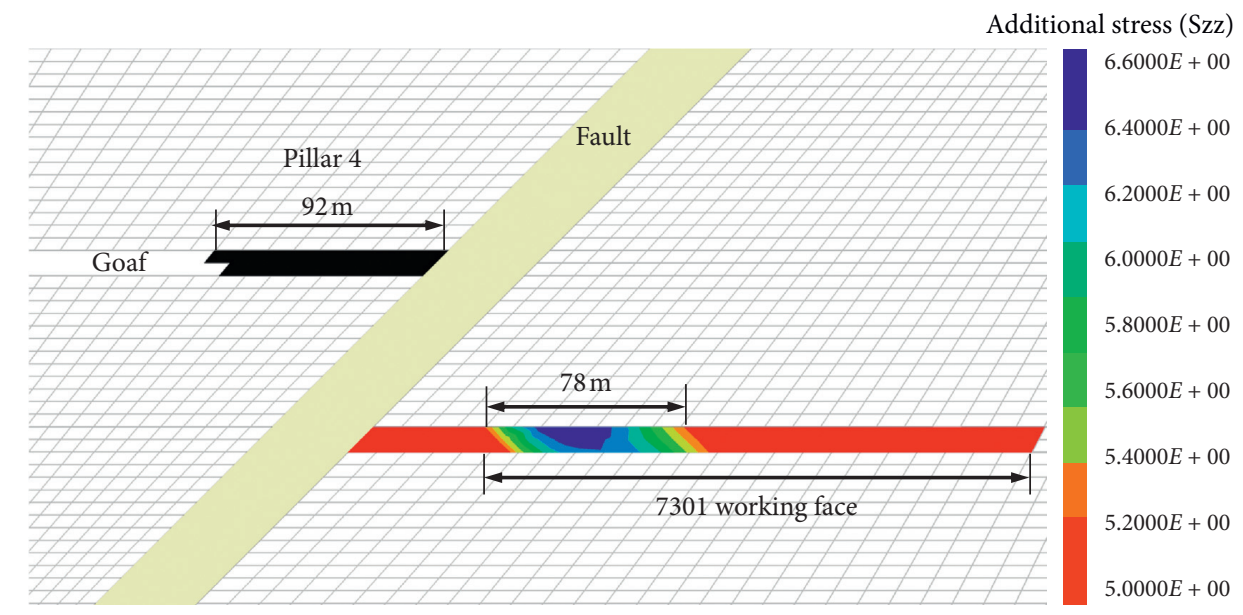

(d)

Figure 6: The width of pillars in the profile and corresponding distribution range of additional stress. (a) The profile along the middle of pillar 1. (b) The profile along the middle of pillar 2. (c) The profile along the middle of pillar 3. (d) The profile along the middle of pillar 4.

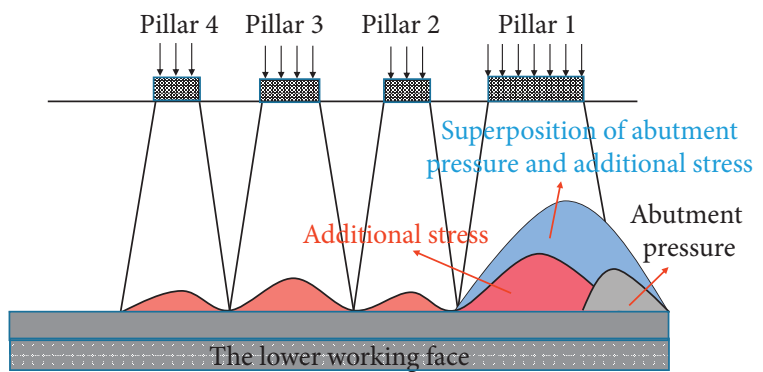

FIGURE 7: The superposition of additional stress and abutment pressure.

gradient stress reaches the peak when the working face is close to the area under the edge of pillar 1, the edge of pillar 4 , and $100 \mathrm{~m}$ from the junction of pillar 1 and pillar 2, respectively. This indicates that the risk of rockburst is the highest when the working face begins to approach the areas under the edge and junction of pillars due to the sharp stress change.

\section{MS Characteristics during Mining under the Pillars}

4.1. Source Locations. The SOS MS monitoring system designed and manufactured by the Institute of Mining Seismology, Polish General Institute of Mining Research is installed in the Zhaolou coal mine. The MS monitor can receive the microearthquake with energy larger than $100 \mathrm{~J}$ and the frequency between 1 and $600 \mathrm{~Hz}$. A total of 4 geophones were installed in the headentry and tailentry of 7301 working face with 2 geophones in each entry, as shown in Figure 1. Figure 10 shows the plan of the MS sources located in the surroundings of the 7301 working face during mining periods underneath pillars 1 and 2 (from August 2019 to February 2020).

Before the working face entering the area affected by pillars (Figure 10(a)), the MS events in front of the coal wall are mainly caused by the abutment pressure. In this period, the energy of most MS events are small (less than $10^{3} \mathrm{~J}$ ), which tends to be evenly distributed along the whole working face without obvious concentration trend. With face continued to advance to the area under the pillar 1 (Figure 10(b)), the number of large energy events (larger than $10^{3} \mathrm{~J}$ ) increases sharply, and the MS events tend to concentrate obviously in the area under pillars 1 and 2, indicating the formation of a high stress concentration area due to the superposition of additional stress and abutment pressure under coal pillars 1 and 2 . As the face advancing to the area under the pillar 2 (Figure 10(c)), the number of large energy events continue to increase, the sources are clustered in the area under the pillar 3 and 4, indicating the concentrated stress in front of the working face rises further, the additional stress transmitted by pillars 3 and 4 is higher than pillars 1 and 2 .

In addition, the distribution range of large energy MS events is consistent with the stress concentration of lower coal seam. According to the comparison of Figures 10(a)$10(\mathrm{c})$, the distance between the farthest MS events and coal wall increases from $206 \mathrm{~m}$ to $426 \mathrm{~m}$ as the face gradually advances to the high stress area. This may be due to the fact that even a slight disturbance is enough to cause the fracture of coal when the coal seam under the pillars has high stress concentration. At the same time, the larger energy sources under pillars 1 and 2 are mainly concentrated on the edge of the working face and close to the headentry side (Figure 10(b)). In comparison, the larger energy sources under pillars 3 and 4 almost distribute in the whole working face-inclined direction (Figure 10(c)). In terms of the scope of the area affected by pillars in lower working face, pillars 3 and 4 are larger than pillars 1 and 2 . The simulation results in Figure 6 are consistent with the conclusion.

4.2. Variation of Total Energy and Events. Until February 2020, the working face has entered the area under pillar 2. Figure 11 shows the change rule of total energy and event 
Zone ZZ stress

$2.8999 E+05$

$5.0000 E+06$

$1.0000 E+07$

$1.5000 E+07$

$2.0000 E+07$

$2.5000 E+07$

$3.0000 E+07$

$3.5000 E+07$

$4.0000 E+07$

$4.5000 E+07$

$5.0000 E+07$

$5.5000 E+07$

$5.7725 E+07$

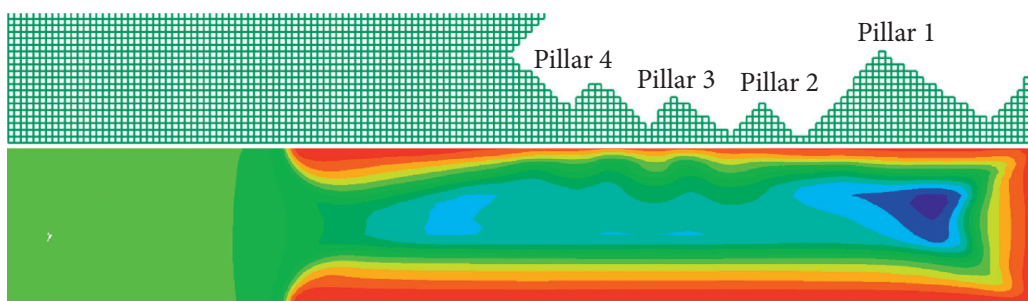

(a)

Zone ZZ stress

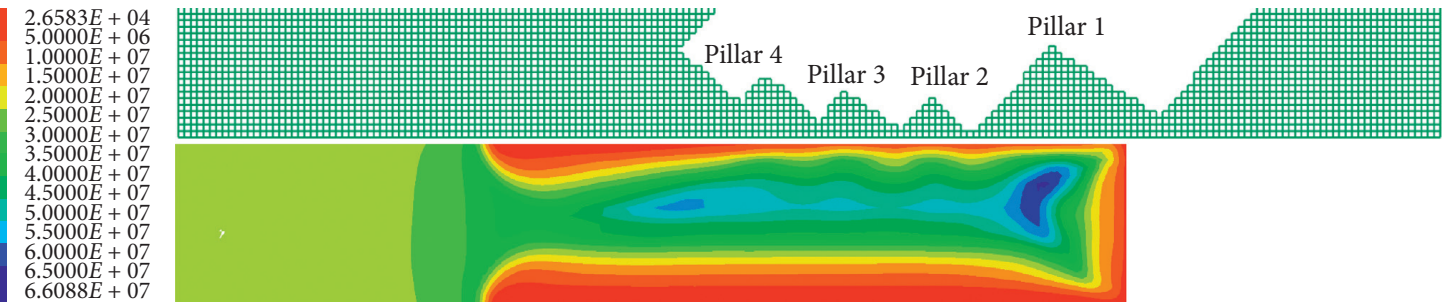

(b)

Zone $\mathrm{ZZ}$ stress

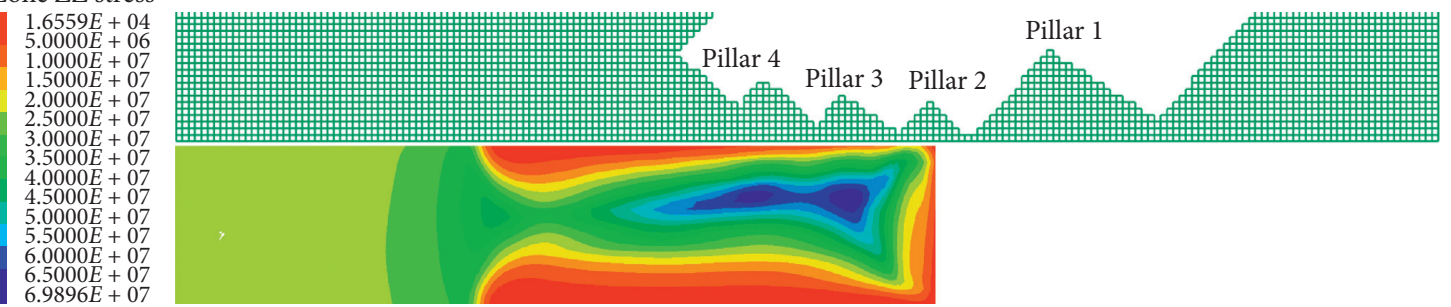

(c)

Zone $\mathrm{ZZ}$ stress

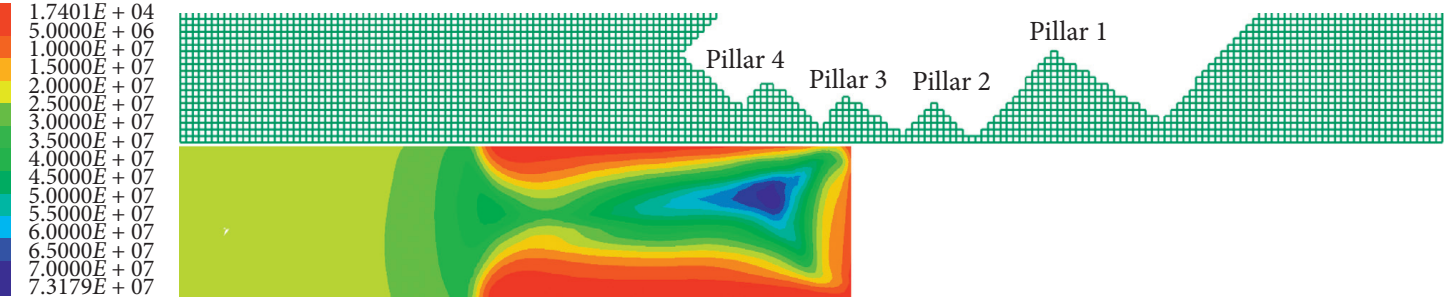

(d)

Zone ZZ stress
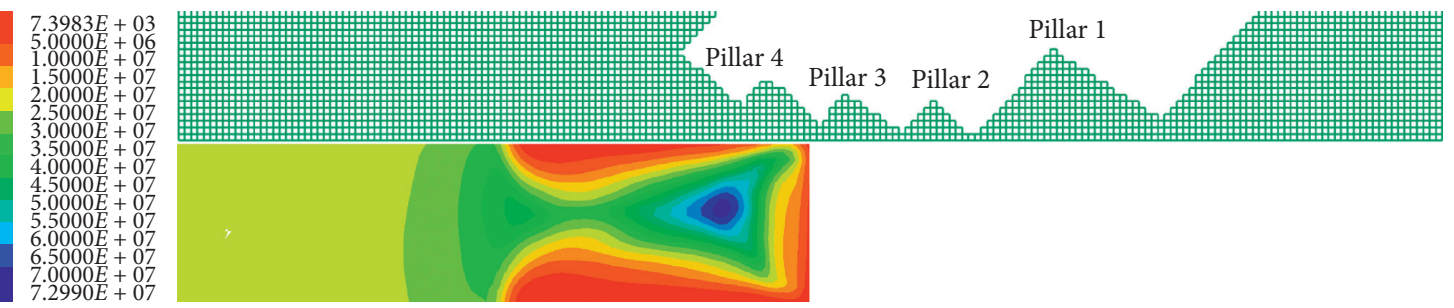

(e)

Figure 8: Continued. 


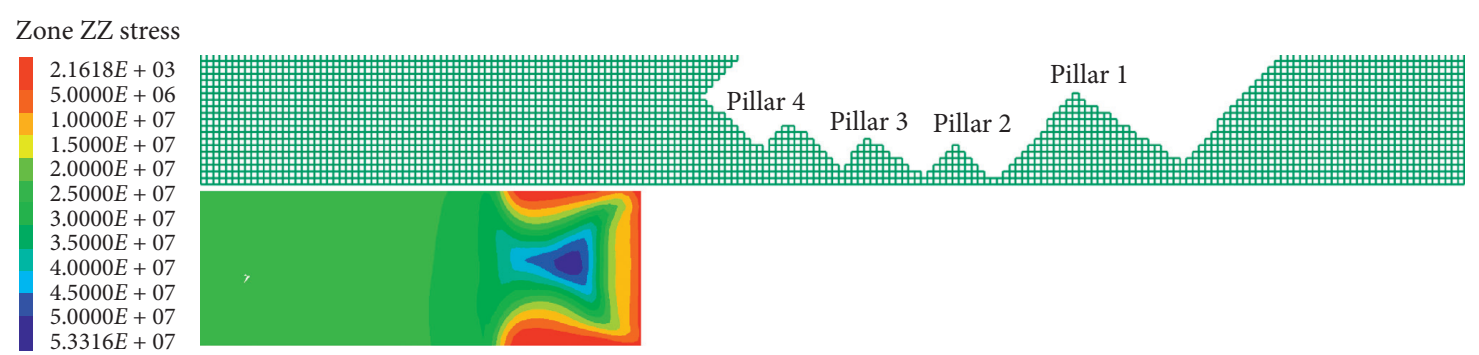

(f)

Figure 8: Vertical stress distribution in different mining stages. (a) Before entering the area under pillars. (b) Advancing to the area under pillar 1. (c) Advancing to the area under pillar 2. (d) Advancing to the area under pillar 3. (e) Advancing to the area under pillar 4. (f) After passing through the affected area by pillars.

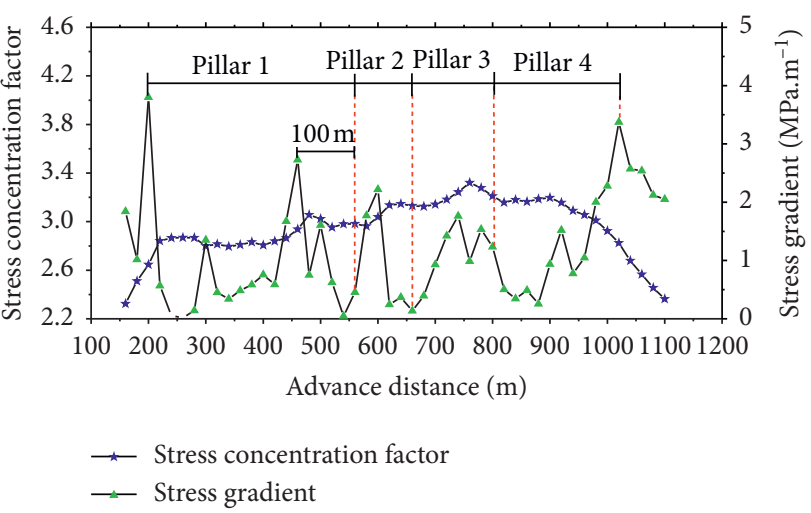

FIGURE 9: Varying curve of vertical stress in different mining stages.

counts of microseisms per day before or after the face passing through underneath pillar 1 . The total energy and event counts reach the peak when face is close to the edge and middle of pillar 1, and the junction of pillar 1 and pillar 2 , respectively. These three positions all correspond to the corner part of the triangular pillar. This may be attributed to the irregular shape of the pillar corner, leading to the sharp change of the gradient stress in the lower working face, and inducing a large number of coal fractures. The change regulation is consistent with the simulation results presented in Figure 9. It shows that the gradient stress of working face under the edge of pillar will change rapidly, which will increase the risk of rockburst during mining.

\subsection{MS Frequency Spectrum Evolution before and after Strong} Mining-Induced Tremors. A large number of laboratory tests and field observations [28-32] indicate that a series of microfractures will occur in coal and rock mass before the occurrence of large fractures and the frequency spectrum distribution of MS events will switch from chaotic mixed high frequency to obvious low frequency. At $15: 18: 50$ on December 2, 2019, when face advanced to the middle of pillar 1, a strong mining-induced shock bump with energy of $6.53 \times 10^{3} \mathrm{~J}$ was received, which was located in the area under the junction of pillar 1 and pillar 2 . The value of stress sensor at the corresponding position rose rapidly from 5.6 $\mathrm{MPa}$ to 16.4 $\mathrm{MPa}$ (variable growth rate of $10.8 \mathrm{MPa}$ ), reaching the red alert, and a strong coal burst occurred in the field. Figure 12 shows the frequency spectrum distributions of the five MS events before and after the strong mining-induced earthquake, as recorded by three geophones close to the source.

It is shown in Figure 12 that before the occurrence of the strong tremor, the frequency spectrum distributions have the characteristics of wide frequency distribution, high central frequency, and low frequency spectrum. It indicates a series of microfractures and a small energy release occurring in coal induced by mining activities. With the continued face advancing, the frequency spectrum increases sharply when the strong mining-induced earthquake occurs at $15: 18: 50$, and the dominant frequencies shift to the low frequency, which indicated that the high stress caused by the superposition of mining stress and additional stress results in the large coal cracks and the release of a large amount of energy. After the strong mining-induced shock bump, the frequency spectrum decreased obviously, the frequency distribution converted from concentration to dispersion, and the dominant frequency changed from low frequency to high frequency. It shows that after the energy release, the stress concentration decreases and only microfracture occurs in the coal. Therefore, the high frequency spectrum, concentrated frequency distribution, and obvious and low dominant frequency can be regarded as the characteristics of strong mining-induced shock bump in high stress concentration area.

4.4. Source Parameters Evolution Mining through the Pillars. The mining-induced tremor is similar to nature earthquake, which all are the phenomenon that the elastic energy is released in the form of wave due to rock break. Thus, the seismology has been applied to the coal mine MS monitoring to predict rockburst. The static stress drop, cumulative apparent volume, and energy index are commonly used parameters to estimate the occurrence of rockburst. The stress difference between stress before and after the rock break is the static stress drop, which reflects stress level in seismic source region and is defined as follows: 


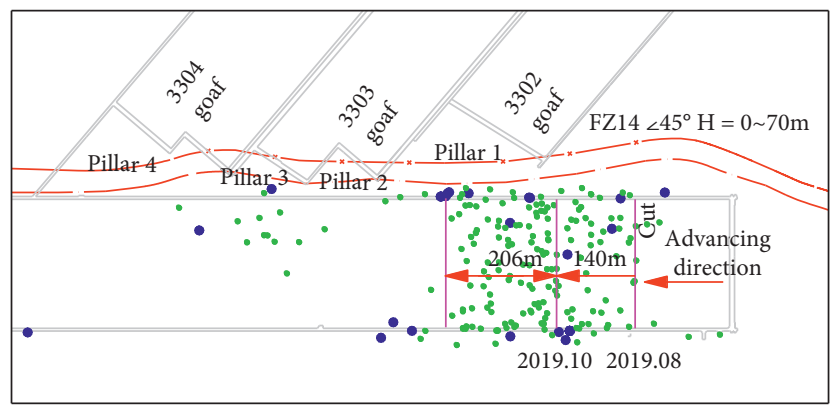

- $0 \sim 10^{3} \mathrm{~J}$

- $10^{3} \sim 10^{4} \mathrm{~J}$

(a)

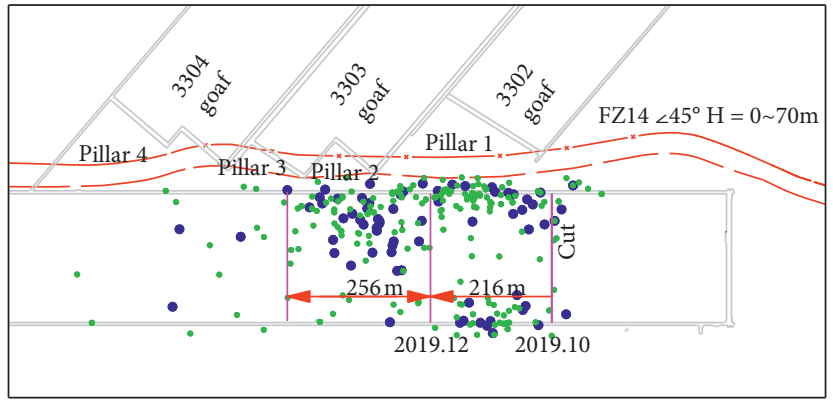

- $0 \sim 10^{3} \mathrm{~J}$

- $10^{3} \sim 10^{4} \mathrm{~J}$

(b)

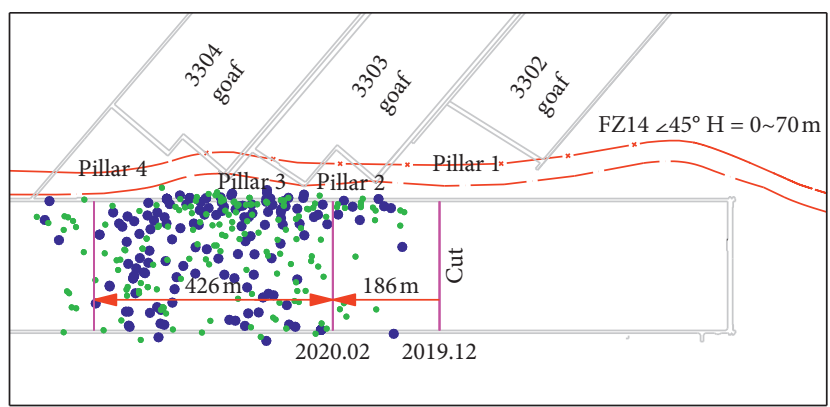

- $0 \sim 10^{3} \mathrm{~J}$

- $10^{3} \sim 10^{4} \mathrm{~J}$

(c)

Figure 10: The MS sources location from August 2019 to February 2020. (a) Sources location before entering under the pillars from August to October 2019. (b) Sources location whenadvancing under the pillar 1 from October to December 2019. (c) Sources location whenadvancing under the pillar 2 from December 2019 to February 2020.

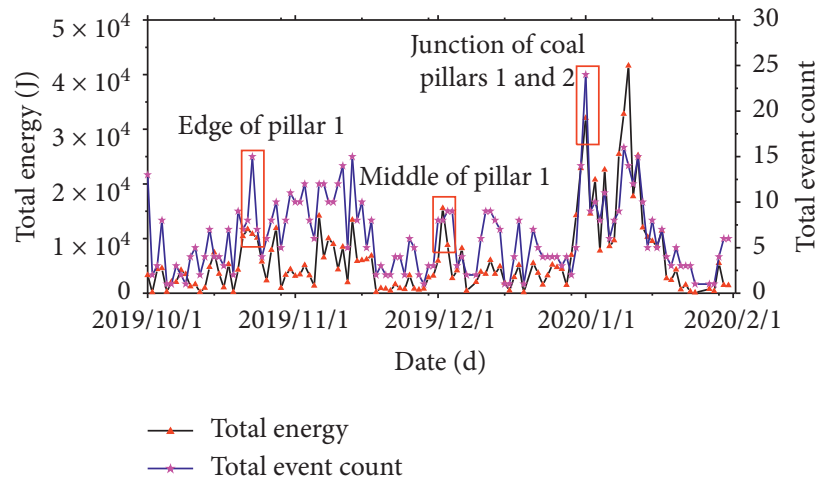

FIGURE 11: Varying curve of total energy and event counts of MS with face under pillars. 


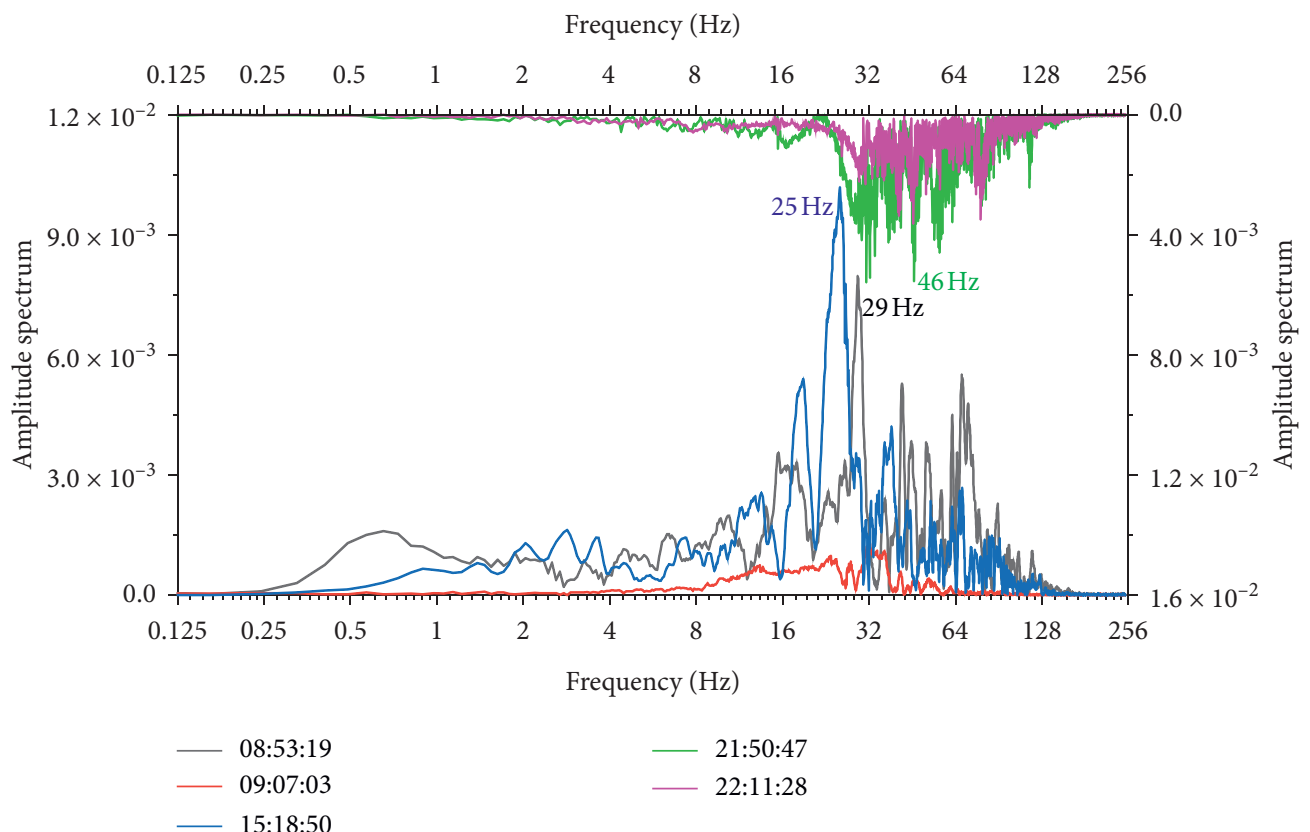

(a)

Frequency $(\mathrm{Hz})$

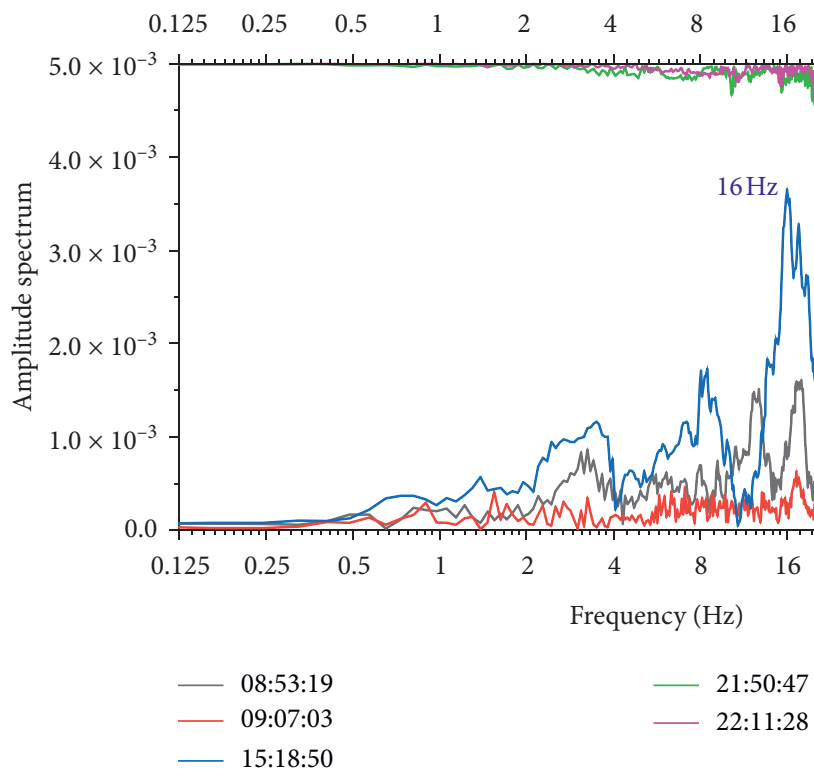

(b)

FIgURE 12: Continued. 


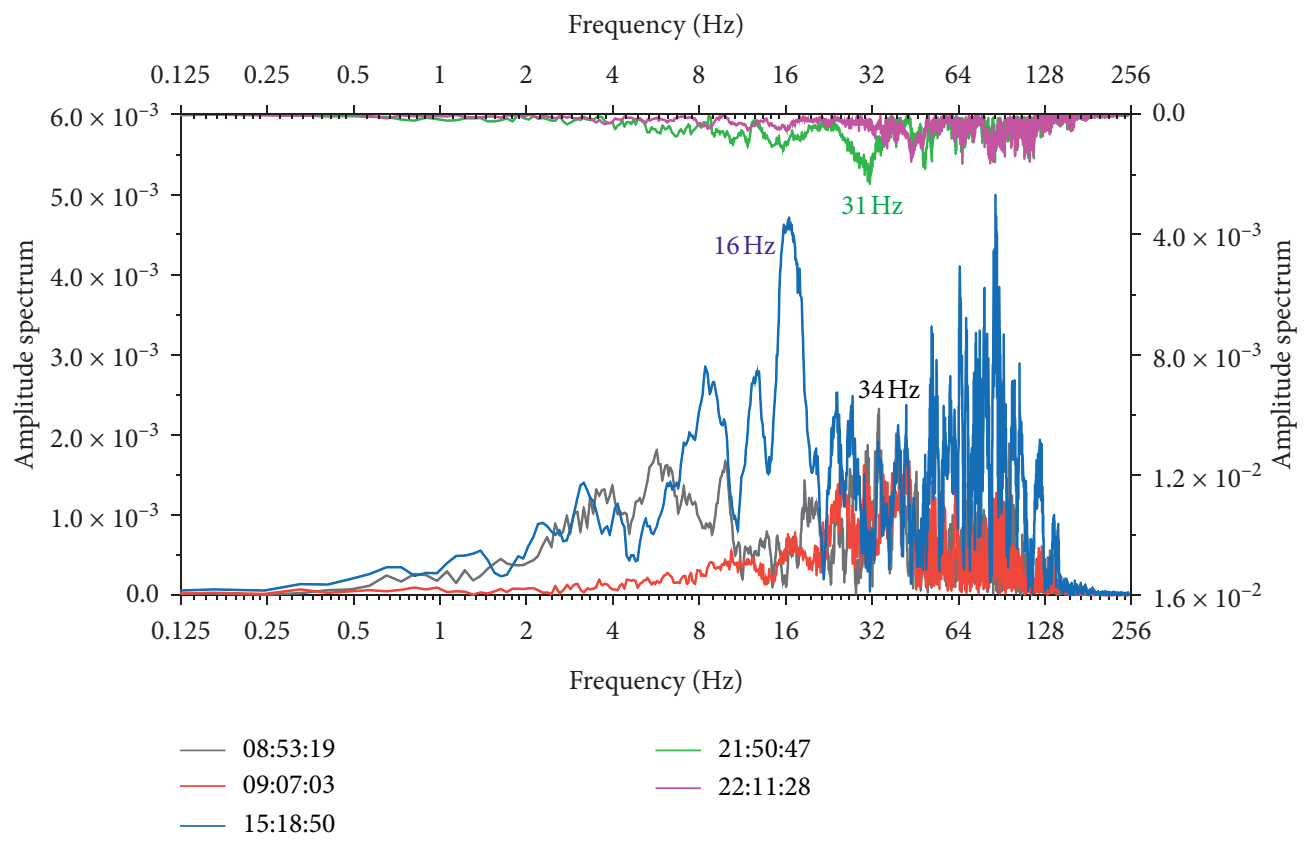

(c)

Figure 12: Frequency spectrum evolution of the MS events. (a) \#16 geophone. (b) \#19 geophone. (c) \#21 geophone.

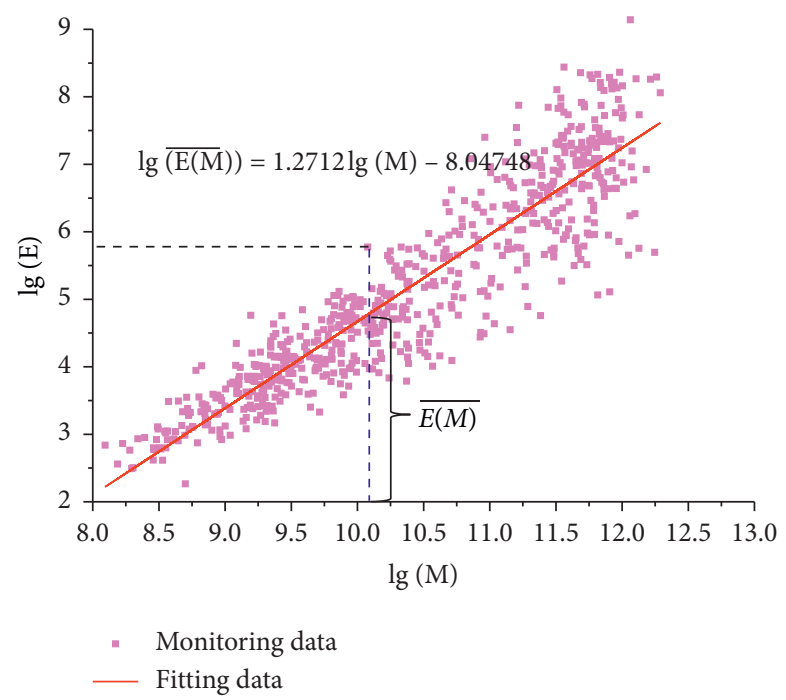

FIGURE 13: Relationship between the energy and seismic moment of the MS events.

$$
\Delta \sigma=\frac{7 M}{16 R^{3}}
$$

where $M_{0}$ is the seismic moment, $R$ is the radius of microseismic source, and $\Delta \sigma$ is the static stress drop.

The apparent volume [33] is the volume of a rock mass that experiences inelastic strain. Cumulative apparent volume is the sum of apparent volume in time. The sharp increase of cumulative apparent volume indicates rock failure, which is defined as follows:

$$
v_{A}=\frac{M^{2}}{2 \mu E}
$$

where $\mu$ is the rigidity of the rock, $E$ is the radiated seismic energy of an even, and $v_{A}$ is the apparent volume. 


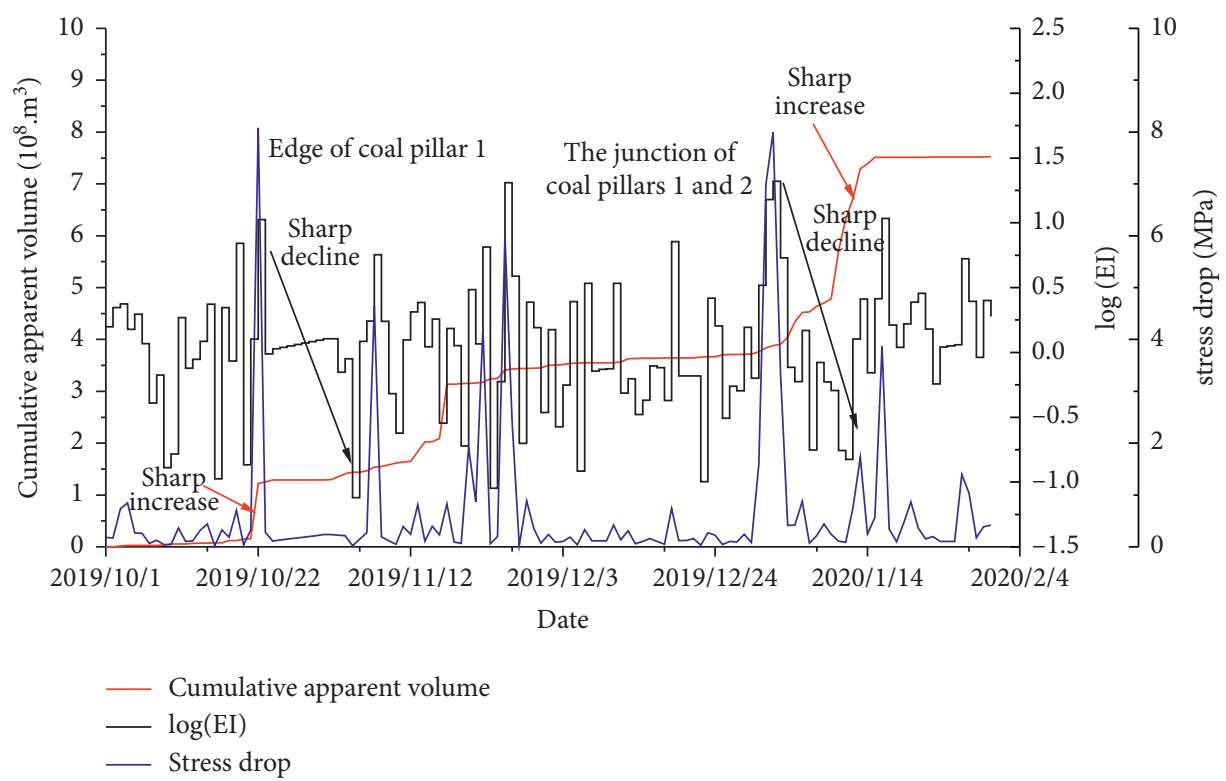

FIgURE 14: Stress drop, cumulative apparent volume, and energy index curves.

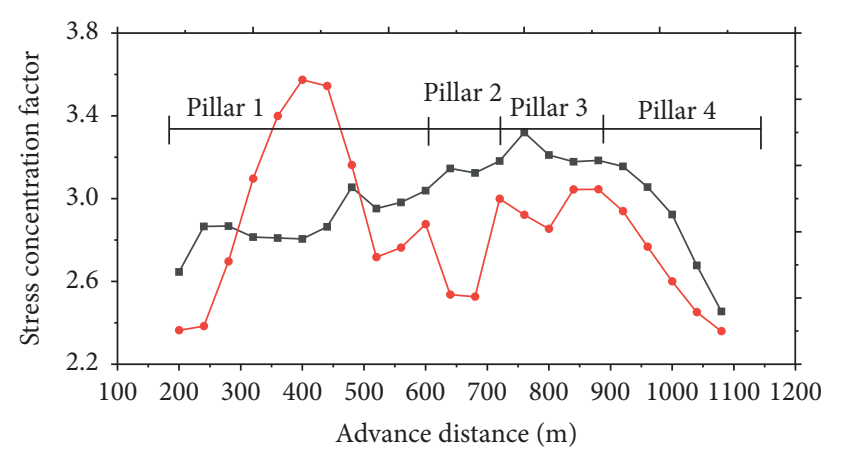

$\rightarrow-$ With fault

$\rightarrow$ Nonfault

FIgURE 15: The stress concentration factor curves with setting or not setting fault.

The energy index of an event [34] is the ratio of the radiated seismic energy of that event to the average radiated seismic energy of events with the same seismic moment, which is defined as follows:

$$
E I=\frac{E}{\overline{E(M)}},
$$

where $\overline{E(M)}$ is the average radiated seismic energy for a given seismic moment and EI is the energy index. Average source radiation energy $\overline{E(M)}$ can be obtained from the relationship between $\lg E$ and $\lg E(M)$ for areas monitored. The relationship between them is shown as follows:

$$
\lg E=c+d \lg \overline{E(M)}
$$

where $c$ and $d$ are the constants that can be obtained to make a linear fit between $\lg E$ and $\lg E(M)$, as shown in Figure 13. The energy index and cumulative apparent volume can be used to describe evolution of stress within rock. Based on the stress-strain curve of rock failure, when the energy index increases gradually and the cumulative apparent volume increases slowly, the rock can be regarded as stable and in the state of energy accumulation; when the energy index decreases sharply and the cumulative apparent volume increases quickly, the rock is broken and in the state of strain softening.

A total of 695 effective MS events were received before and after the working face pushed through the area under pillar 1 (October 2019 to February 2020). First, filtering is applied to the waveform of these events to remove noise signals, then the seismic moment $(M)$ and radiated seismic energy $(E)$ of each event can be calculated based on the waveform characteristics. Finally, the change of the static stress drop, cumulative apparent volume, and energy index with time are obtained according to the formulas (1), (2), (3), and (4) which is shown in Figure 14.

It can be seen from Figure 14, before working face advances to the area under edge of coal pillar 1, the stress drop and energy index fluctuate at a small range, cumulative apparent volume increases slowly, which means that rock mass in the monitoring area is in the state of energy accumulation. On October 22, 2019, the stress drop of events reaches a peak; correspondingly, the MS sources mainly concentrate at area under the edge and middle of pillar 1; the stress drop reflects the stress level in seismic source region, and the high stress drop indicates the static high stress concentration. Meanwhile, the energy index declines sharply and cumulative apparent volume increases quickly, and it is the typical potential damage of rock mass and strain-softening stage. It indicates the surrounding rock has been broken with strength decrease and the deformation increase. Similarly, the same change is followed by stress drop, energy index, and cumulative apparent volume when the working face advances to the area under junction of coal pillars 1 and 2. From January 1 to January 
10,2020 , the working face is gradually pushed through the area under the junction of pillar 1 and pillar 2. During this period, the stress drop reaches a peak value, the energy index decreases significantly, and the cumulative apparent volume increases rapidly, indicating that the rock mass failure in the monitoring area is gradually increasing. As a consequence of the above points, when the working face is close to the area under edge and junction of pillars, the stress drop will reach the peak value, the energy index decreases sharply, and the cumulative apparent volume increases sharply, and the risk of rockburst will increase. This is consistent with the results of numerical simulation in Figure 9.

\section{Discussion}

Fault is the initial fracture of stratum and formed in the process of tectonic movement. The discontinuity of the fault blocks the stress transfer in the stratum (the nonuniform stress distributions in the stratum) and causes the tectonic stress concentration near the fault. The superposition of the tectonic stress near the FZ14 fault, the additional stress transferred by pillars, and the abutment pressure will greatly improve the risk of rockburst in the 7310 working face. Figure 15 shows the stress concentration factor curves of the two cases setting or not setting faults in the numerical model, respectively. It can be seen from Figure 15, excepting when face is under coal pillar 1, the stress concentration factor with fault is generally higher than that without fault, indicating the tectonic stress near the fault has significant impact on the mining. However, the reasons that the stress concentration factor behaves differently when face is under pillar 1 may be as follows: compared with setting fault, without fault, the peak stress in pillar 1 is closer to the working face, and the peak stress in pillar 1 is the highest; thus the additional stress will increase greatly, and the influence of that on the working face is greater than the tectonic stress when fault is set. It also shows that it is necessary to consider the thickness of fault in this numerical simulation.

\section{Conclusions}

(1) Among pillars, the width of the goaf on both sides of pillar 1 is wider, which leads to the higher caving of the stratum and the larger area of the suspended roof. Therefore, the concentration stress in pillar 1 is higher, and additional stress transferred by pillar 1 is larger at the working face. But there is more distance between the areas with the peak stress and working face; thus the area affected by pillar 1 is smaller. Contrary to pillar 1, the stress peaks of pillars 2, 3, and 4 are closer to the working face, so the area affected by pillars 2,3 , and 4 in the working face is larger.

(2) The numerical simulation results show that the gradient stress reaches the peak value when face is close to the area under the edge of coal pillar 1, the edge of coal pillar 4, and junction of pillars 1 and 2 . At the same time, the field MS monitoring data also show that the total energy and event counts reach the peak when face is close to the area under the edge of pillar 1, the middle of pillar 1 , and the junction of pillar 1 and coal pillar 2, respectively. It can be concluded that the area under the edge and the junction of pillars are stress concentration areas, which leads to the sharp change of the gradient stress in lower working face and very likely induce rockburst.

(3) The increase of the concentrated stress in the coal seam under the pillars will lead to strong coal fracture and induce high energy MS events; meanwhile, the corresponding frequency spectrum distributions converts from dispersed to concentrate, and the dominant frequency gradually becomes obvious and transfers from high frequency to low frequency. These are the characteristics of the occurrence of strong mining-induced shock bump

(4) Source parameters monitoring based on seismology can be used to predict rockburst. The evolution of static stress drop, cumulative apparent volume, and energy index before and after the working face pushed through the area under pillar 1 are analyzed. Results indicate that when the working face is close to the area under edge and junction of pillars, the stress drop reaches the peak value, the energy index decreases sharply, the cumulative apparent volume increases sharply, and the risk of rockburst increases.

(5) The FZ14 fault also affects the safety of working face. The superposition of the tectonic stress near the FZ14 fault, the additional stress transferred by pillars, and the abutment pressure formed in the mining process greatly improve the risk of rockburst at the working face.

\section{Data Availability}

The data in this manuscript are available from the authors.

\section{Conflicts of Interest}

The authors declare that there are no conflicts of interest regarding the publication of this paper.

\section{Acknowledgments}

The authors gratefully wish to acknowledge the collaborative funding support from the National Natural Science Foundation of China (51574225), the Fundamental Research Funds for the Central Universities (YC150001), and a project funded by the Priority Academic Program Development of Jiangsu Higher Education Institutions (PAPD). 


\section{References}

[1] R. Howarth and N. R. Monger, "Multi-seam working," Australian Coal Mining Practice-Monograph 12 - 3rd ed. AusIMM, pp. 376-391, 2009.

[2] Q. X. Huang, Y. P. He, and J. Cao, "Experimental investigation on crack development characteristics in shallow coal seam mining in China," Energies, vol. 12, no. 7, pp. 1-16, 2019.

[3] H. Guo, L. Yuan, B. Shen, Q. Qu, and J. Xue, "Mining-induced strata stress changes, fractures and gas flow dynamics in multi-seam longwall mining," International Journal of Rock Mechanics and Mining Sciences, vol. 54, pp. 129-139, 2012.

[4] A. M. S. Iwanec, J. P. Carter, and J. P. Hambleton, "Geomechanics of subsidence above single and multi-seam coal mining," Journal of Rock Mechanics and Geotechnical Engineering, vol. 8, no. 3, pp. 304-313, 2016.

[5] B. Ghabraie, G. Ren, and J. V. Smith, "Characterising the multi-seam subsidence due to varying mining configuration, insights from physical modelling," International Journal of Rock Mechanics and Mining Sciences, vol. 93, pp. 269-279, 2017.

[6] J. W. Cassie, P. B. Cartwright, R. Altounyan et al., "Coal pillar behaviour from underground stress measurements," in Proceedings of the 9th International Congress on Rock Mechanics, pp. 1347-1354, Paris, France, August 1999.

[7] H. Wagner, "Pillar design in coal mines," Journal of the South African Institute of Mining \& Metallurgy, vol. 80, no. 1, pp. 37-45, 1980.

[8] S. Jayanthu, T. N. Singh, and D. P. Singh, "Stress distribution during extraction of pillars in a thick coal seam," Rock Mechanics and Rock Engineering, vol. 37, pp. 171-192, 2004.

[9] R. K. Wattimena, S. Kramadibrata, I. D. Sidi, and M. A. Azizi, "Developing coal pillar stability chart using logistic regression," International Journal of Rock Mechanics and Mining Sciences, vol. 58, pp. 55-60, 2013.

[10] M. Khanal, D. Adhikary, C. Jayasundara, and R. Balusu, "Numerical study of mine site specific multiseam mining and its impact on surface subsidence and chain pillar stress," Geotechnical and Geological Engineering, vol. 34, no. 1, pp. 217-235, 2015.

[11] G. Murali Mohan, P. R. Sheorey, and A. Kushwaha, "Numerical estimation of pillar strength in coal mines," International Journal of Rock Mechanics and Mining Sciences, vol. 38, no. 8, pp. 1185-1192, 2001.

[12] P. K. Kaiser, B. Kim, R. P. Bewick, and B. Valley, "Rock mass strength at depth and implications for pillar design," Mining Technology, vol. 120, no. 3, pp. 170-179, 2011.

[13] M. Alber and J. Heiland, "Investigation of a limestone pillar failure Part 2: stress history and application of fracture mechanics approach," Rock Mechanics and Rock Engineering, vol. 34, pp. 187-199, 2001.

[14] G. S. Esterhuizen, D. R. Dolinar, and J. L. Ellenberger, "Pillar strength in underground stone mines in the United States," International Journal of Rock Mechanics and Mining Sciences, vol. 48, pp. 42-50, 2001.

[15] A. M. Suchowerska, R. S. Merifield, and J. P. Carter, "Vertical stress changes in multi-seam mining under supercritical longwall panels," International Journal of Rock Mechanics and Mining Sciences, vol. 61, pp. 306-320, 2013.

[16] J. X. Yang, C. Y. Liu, B. Yu, and F. F. Wu, "The effect of a multi-gob, pier-type roof structure on coal pillar load-bearing capacity and stress distribution," Bulletin of Engineering Geology and The Environment, vol. 74, no. 4, pp. 1267-1273, 2014.
[17] X. Liu, X. M Li, and W. D. Pan, "Analysis on the floor stress distribution and roadway position in the close distance coal seams," Arabian Journal of Geosciences, vol. 9, no. 83, pp. 1-8, 2016.

[18] H. Z. Zhu, L. Ping, and Z. Y. Tong, "Numerical simulation research and application on protected layer pressure relief affection under different coal pillar width," Procedia Engineering, vol. 84, pp. 818-825, 2014.

[19] J.-X. Yang, C.-V. Liu, B. Yu, and F.-F. Wu, "Calculation and analysis of stress in strata under gob pillars," Journal of Central South University, vol. 22, no. 3, pp. 1026-1036, 2015.

[20] B. Yu, Z. Zhang, T. Kuang, and J. Liu, "Stress changes and deformation monitoring of longwall coal pillars located in weak ground," Rock Mechanics and Rock Engineering, vol. 49, no. 8, pp. 3293-3305, 2016.

[21] R. X. Xue, Z. Z. Liang, N. W. Xu, and L. L. Dong, "Rockburst prediction and stability analysis of the access tunnel in the main powerhouse of a hydropower station based on microseismic monitoring," International Journal of Rock Mechanics and Mining Sciences, vol. 126, pp. 1-13, 2020.

[22] Y. Zhao, T. Yang, P. Zhang, J. Zhou, Q. Yu, and W. Deng, "The analysis of rock damage process based on the microseismic monitoring and numerical simulations," Tunnelling and Underground Space Technology, vol. 69, pp. 1-17, 2017.

[23] G. K. Ghosh and C. Sivakumar, "Application of underground microseismic monitoring for ground failure and secure longwall coal mining operation: a case study in an Indian mine," Journal of Applied Geophysics, vol. 150, pp. 21-39, 2018.

[24] G. Cheng, T. Ma, C. Tang, H. Liu, and S. Wang, "A zoning model for coal mining - induced strata movement based on microseismic monitoring," International Journal of Rock Mechanics and Mining Sciences, vol. 94, pp. 123-138, 2017.

[25] T.-H. Ma, C.-A. Tang, S.-B. Tang et al., "Rockburst mechanism and prediction based on microseismic monitoring," International Journal of Rock Mechanics and Mining Sciences, vol. 110, pp. 177-188, 2018.

[26] P. M. Benson, S. Vinciguerra, P. G. Meredith, and R. P. Young, "Spatio-temporal evolution of volcano seismicity: a laboratory study," Earth and Planetary Science Letters, vol. 291, no. 1-2, pp. 315-323, 2010.

[27] A. I. Sainoki and H. S. Mitri, "Simulating intense shock pulses due to asperities during fault-slip," Journal of Applied Geophysics, vol. 103, pp. 71-81, 2018.

[28] H. Spetzler, C. Sondergeld, G. Sobolev, and B. Salov, "Seismic and strain studies on large laboratory rock samples being stressed to failure," Tectonophyncs, vol. 144, no. 1-3, pp. 55-68, 1987.

[29] Y. Liu, C.-P. Lu, B. Liu, H. Zhang, and H.-Y. Wang, "Experimental and field investigations on seismic response of joints and beddings in rocks," Ultrasonics, vol. 97, pp. 46-56, 2019.

[30] C.-P. Lu, B. Liu, B. Liu, Y. Liu, H.-Y. Whang, and H. Zhang, "Anatomy of mining-induced fault slip and a triggered rockburst," Bulletin of Engineering Geology and the Environment, vol. 78, no. 7, pp. 5147-5160, 2019.

[31] H. Wang, A. Dyskin, E. Pasternak, P. Dight, and M. Sarmadivaleh, "Effect of the intermediate principal stress on 3-D crack growth," Engineering Fracture Mechanics, vol. 204, pp. 404-420, 2018.

[32] F. Cappa and J. Rutqvist, "Modeling of coupled deformation and permeability evolution during fault reactivation induced by deep underground injection of CO," International Journal of Greenhouse Gas Control, vol. 5, no. 2, pp. 336-346, 2010. 
[33] A. J. Mendecki, R. P. Young, Real time quantitative seismicity in mines," in Proceedings of Sixth International Symposium on Rockburst and Seismicity in Mines, pp. 287-296, A. A. Balkema, Rotterdam, Netherland, August 1993.

[34] V. A. Aswegen and A. G. Butler, R. P. Young, Application of quantitative seismology in South African gold mines," in Proceedings of the 3rd International Symposium on Rockbursts and Seismicity in Mines, pp. 261-266, A. A. Balkema, Rotterdam, Netherland, August 1993. 